\title{
Pulsed glow discharge time of flight mass spectrometry for the screening of polymer-based coatings containing brominated flame retardants
}

\author{
Claudia González de Vega, ${ }^{a}$ Lara Lobo, ${ }^{a}$ Beatriz Fernández, ${ }^{* a}$ Nerea Bordel, ${ }^{b}$ Rosario Pereiro ${ }^{a}$ \\ and Alfredo Sanz-Medel ${ }^{* a}$
}

\author{
Received 13th October 2011, Accepted 28th November 2011 \\ DOI: $10.1039 / \mathrm{c} 2 \mathrm{ja10300a}$
}

\begin{abstract}
There is an increasing concern regarding the toxicity, environmental distribution and impact of organic compounds employed today as flame retardants. Along these lines, the potential of radiofrequency pulsed glow discharge (rf-PGD) time-of-flight mass spectrometry for mass spectrometric fingerprinting and quantification of brominated flame retardants (BFRs) into polymers is investigated here.

Tetrabromobisphenol A was chosen as a "model" BFR compound for system optimisation and analytical characterisation purposes. After optimisation of power and pressure operation conditions of the rf-PGD, $15 \mathrm{~W}$ forward power and $200 \mathrm{~Pa}$ were chosen with the aim of attaining good sensitivity for elemental and polyatomic ions and long-term signal stability. Then, analytical performance of microand milli-second GD pulse regimes was compared and better detection limits were obtained using the millisecond pulse regime (a higher number of polyatomic ions was observed as well). Under the selected optimum conditions, linear calibration graphs were obtained for elemental bromine as well as for several polymer fragments. Limits of detection well below $0.1 \%$ were obtained both for elemental bromine and for the fragments investigated. Finally, a comparison of the mass spectra obtained for some polymeric samples containing different BFR compounds was carried out. The signals of polyatomic ions, related to the BFRs, can be successfully applied to the identification and discrimination among the different polymers.
\end{abstract}

\section{Introduction}

Brominated flame retardants (BFRs), a major type of chemical flame retardants, are today widely used in electric and electronic equipment, construction material, and in transportation and textile applications. ${ }^{1}$ BFRs are added into polymeric materials, such as plastics and polyurethane foam, to decrease their risk of fire. These compounds can leach out into the air or be dispersed into aquatic environments from landfills. Tetrabromobisphenol A (TBBPA) and polybrominated diphenyl ethers (PBDEs) are the most widely used BFRs in commercial products. ${ }^{2}$ The knowledge of some BFRs toxicity, e.g. PBDEs and polybrominated byphenyls (PBBs), is still insufficient to predict their potential health risks. However, several congeners are associated with hazardous effects on humans and environment (e.g. neurotoxicity and endocrine disruption). ${ }^{3}$ The European Commission Directive 2002/95/EC on the "restriction of the use of certain hazardous substances in electrical and electronic

${ }^{a}$ Department of Physical and Analytical Chemistry, Faculty of Chemistry, University of Oviedo, Julian Clavería, 8, 33006 Oviedo, Spain. E-mail: fernandezbeatriz@uniovi.es; asm@uniovi.es; Fax: +34 9851031 25; Tel. +34985103474

${ }^{b}$ Department of Physics, Faculty of Science, University of Oviedo, Calvo Sotelo s/n, 33007 Oviedo, Spain equipment" (RoHS) ${ }^{4}$ prohibits the usage of certain PBDEs in electric and electronic devices since July 2006. Moreover, Commission Decision 2005/618/EC 5 specifies a limit of $1 \mathrm{~g} \mathrm{~kg}^{-1}$ for the sum of PBDEs and PBBs in plastics. Thus, the need for new analytical strategies for the rapid, simple and reliable detection of BFRs in materials and wastes, potentially containing such flame retardants, is clear.

Several analytical methods have been used for the analysis of BFRs, including gas and liquid chromatography coupled to mass spectrometry. ${ }^{6-8}$ However, those reported methods have some analytical limitations, such as complex pre-treatment processes and long analysis time. Moreover, accurate quantification of BFRs in plastics can only be achieved if several challenges in the analysis are successfully handled, such as suitable grinding or milling of the sample, selective analytes extraction, as well as problems related to photolytic degradability or thermal instability. In principle, the use of solid-state spectrometric techniques, such as secondary ion (SIMS) and glow discharge (GDMS) mass spectrometry, ${ }^{9}$ allow valuable information to be obtained about polymers containing BFRs without virtually any sample preparation step (this means short-time analysis, low risk of contamination and spatial resolution capability). Although SIMS shows an excellent potential for analysis of polymers, ${ }^{\mathbf{1 0}}$ it also presents some drawbacks, particularly severe matrix effects, 
its high cost and long-time analysis. On the other hand, GD-MS offers an alternative tool for such rapid and high sensitive analysis of polymers. ${ }^{11,12}$ It is not surprising that GD-MS application is increasing nowadays because it offers several interesting features, including fast sputtering rate, low matrix effects, multielemental capability and low limits of detection. ${ }^{13}$

Additionally, radiofrequency (rf) pulsed GDs (PGDs) have been recently proposed as an attractive analytical alternative to the more common GD operation mode which uses continuous powering of the discharge. ${ }^{14}$ The combination of PGDs with a time-of-flight mass spectrometer (ToFMS) permits the quasisimultaneous detection of ions along the GD pulse period and, thus, the observation of the time domains with different ionization mechanisms in the formed plasma (denoted as pre-peak, plateau and after-peak regions). This allows the selection of the integration time detection window that provides the highest analyte signal with minimum spectral interferences ${ }^{13,15}$ and the possibility to obtain both elemental and molecular information. Recently, the analytical capabilities of rf-PGDs-ToFMS have been successfully investigated for solid-state speciation $^{16-18}$ and polymers characterisation. ${ }^{19-21}$ For instance, Robertson-Honecker et al. ${ }^{16}$ reported the direct speciation of chromium in solid state samples in order to distinguish trivalent and hexavalent forms of Cr. A millisecond rf-PGD-ToFMS system was used in this study and several $\mathrm{Cr}_{x} \mathrm{O}_{y}{ }^{+}$cluster ions and hydrogenated species were detected for both chromium oxides, although their number, relative intensity, and distribution varied depending on the particular $\mathrm{Cr}$ oxide. Thus, cluster ions were employed for differentiation between the trivalent and hexavalent forms of $\mathrm{Cr}$.

Concerning polymer characterisation, some preliminary studies of GD-ToFMS for the analysis of BFRs in plastics ${ }^{12}$ and other polymeric samples ${ }^{19-21}$ have been carried out, not only using traditional low pressure GD sources but also working with atmospheric pressure GDs. ${ }^{22}$ Li et al. ${ }^{12}$ reported that both atomic and molecular species were detected for several bromine-containing flame-retardant plastics. However, quantitative results were only possible for elemental bromine since the molecular species exhibited very low signals and, moreover, BFRs identification was not possible. Tuccitto et al. ${ }^{19,20}$ have recently shown the ability of rf-PGD-ToFMS for molecular depth profiling of polymers deposited on silicon. Thin films of different polymers were successfully resolved with retention of molecular information along the profile. Furthermore, some formed polyatomic ions have proved to be useful to identify the different polymeric layers, confirming that layers having similar elemental composition but different polymer structures could be differentiated. Not only positive but also negative ions can be used for such characterisation purposes. Canulescu et al. ${ }^{21}$ showed also that the negative ion mode in a ToFMS detector may offer a better sensitivity for some elements (e.g. halogens), a reduced background and complementary information compared to the corresponding positive ion mode.

In this work we investigated the capabilities of rf-PGDToFMS for mass spectrometric fingerprinting of polymers containing different BFRs as a possible and effective screening tool for the rapid estimation of BFRs presence. A comparative study has been performed for micro- and milli-second pulse regimes, while elemental and molecular species have been tested for quantification purposes. Moreover, the presence of polyatomic ions related to the BFRs structure or formed in the plasma after sputtering of the polymer material was used for the identification and discrimination between different BFRs. Finally, the data obtained by rf-PGD-ToFMS were also processed with linear discriminant analysis (LDA), ${ }^{23}$ a tool widely used for multivariate statistical analysis, for the differentiation among the polymers containing BFRs.

\section{Experimental}

\section{Reagents and materials}

Bisphenol A [2,2-bis(5-hydroxyphenyl)propane], phloroglucinol, $3,3^{\prime}, 5,5^{\prime}$-tetrabromobisphenol A (TBBPA), Decabromodiphenyl ether (Deca-BDE), 4,4'-dibromo-1,1'-biphenyl $\left(4,4^{\prime}\right.$-BB) and 1,2,5,6,9,10-hexabromocyclododecane (HBCD) were purchased from Sigma-Aldrich (Steinheim, Germany). Diphenylmethane4,4'-diisocyanate (MDI) and tetrahydrofurane (THF) were provided by Merck (Darmstadt, Germany) and Chromanorm (Leuven, Belgium), respectively. These reagents were used to synthesize bromine-containing polymers. Electronic quality silicon wafers $(525 \pm 25 \mu \mathrm{m}$ thickness) from University Wafer (USA) were used as support for the polymeric coatings.

High-purity argon (99.999\% minimum purity) from Air Liquide (Avilés, Spain) was employed as plasma gas for rf-PGDToFMS experiments.

\section{Preparation of the polymers}

Polyurethanes were prepared from bisphenol A, TBBPA (or the corresponding BFR: Deca-BDE, $4,4^{\prime}-\mathrm{BB}$ or HBCD) and MDI as functional monomers, phloroglucinol as an additional crosslinker and THF as a solvent. In order to prepare polymers with different concentrations of bromine, the amounts of bisphenol A and the selected BFR (TBBPA, Deca-BDE, 4,4'-BB or HBCD) were varied, taking care to keep an equimolecular relationship between hydroxyl and diisocyanate groups. Table 1 collects the amounts of each compound used to obtain all the polymeric coatings and their corresponding bromine concentrations (w/w $\%$ ). The corresponding blanks (polymers without BFRs) were also prepared in all cases.

Nitrile gloves, protective clothing and safety glasses were worn all the time while preparing the polymers. A respirator equipped

Table 1 Amounts of reagents used for the synthesis of polymers containing different percentages of bromine. BFRs employed: TBBPA, 4,4'BB, Deca-BDE and HBCD

\begin{tabular}{llccl}
\hline $\begin{array}{l}\text { Br } \\
(\mathrm{w} / \mathrm{w} \%)\end{array}$ & $\begin{array}{l}\text { Diphenylmethane- } \\
4,4^{\prime} \text {-diisocianate/mg }\end{array}$ & \multicolumn{3}{l}{ Phloroglucinol/ Bisphenol } \\
$\mathrm{mg}$ & 70 & $\mathrm{~A} / \mathrm{mg}$ & $\mathrm{BFR} / \mathrm{mg}$ \\
\hline 27.9 & 87 & 70 & 94 & $\mathrm{TBBPA} / 227$ \\
16.2 & 87 & 70 & 140.3 & $\mathrm{TBBPA} / 114$ \\
8.8 & 87 & 70 & 163.7 & $\mathrm{TBBPA} / 57$ \\
4.6 & 87 & 70 & 175.5 & $\mathrm{TBBPA} / 29$ \\
2.4 & 87 & 70 & 181.4 & TBBPA/14 \\
0.6 & 87 & 70 & 185.8 & TBBPA/3 \\
27.9 & 87 & 70 & 187.3 & $4,4^{\prime}-\mathrm{BB} / 412$ \\
27.9 & 87 & 70 & 187.3 & Deca-BDE/173 \\
27.9 & 87 & 70 & 187.3 & HBCD/205 \\
0 & 87 & 187.3 & 0 \\
\hline
\end{tabular}


with two organic vapour/particulate filters was used. Hazardous wastes were collected, stored in glass containers, labelled and sent to a waste management company. To prepare the polymer, the solid reagents were weighed, introduced into glass vials and dissolved in $5 \mathrm{ml}$ of THF. Then, $2 \mathrm{ml}$ was put and dispersed on the $\mathrm{Si}$ wafer. The solvent was allowed to evaporate at room temperature for at least $24 \mathrm{~h}$. The final thickness of the polymeric coating into the $\mathrm{Si}$ support was in the range of 4-5 $\mu \mathrm{m}$ (the thickness of the layers was determined by profilometry measurements using a mechanical profilometer from Ambios Technology, USA).

\section{Instrumentation: rf-PGD-ToFMS}

The rf-PGD-ToFMS instrument consists of a rf-GD bay unit from Horiba Jobin Yvon (Longjumeau, France) coupled to a fast orthogonal time-of-flight mass spectrometer (TOFWERK, Switzerland) with a microchannel plate detector. ${ }^{24}$ Additionally, an interface consisting of two extraction cones connects the GD source to the ToFMS. This interface allows extraction and focusing of the ions as well as reduction of the pressure between the GD source and the mass analyser. A pure copper modified Grimm type GD source (EMPA, Switzerland), with a $4 \mathrm{~mm}$ diameter anode and a $2.5 \mathrm{~mm}$ inner diameter flow tube, was used. The power is supplied to the GD through the back side of the sample by a rf-power generator operating at 13.56 $\mathrm{MHz}$ and a refrigerating disc is used to keep the samples at low temperatures $\left(<5{ }^{\circ} \mathrm{C}\right)$. The rf power supply can be run either in pulsed mode with a frequency between $0.1 \mathrm{~Hz}$ and 10 $\mathrm{kHz}$ and a pulse width from $50 \mu$ s up to several milliseconds or in non-pulsed mode. The frequency and the pulse width can be selected independently. Therefore, the GD duty cycle, which is the ratio between pulse width and the pulse period, can be optimised depending on the application. Pulses from $100 \mu$ s up to $2 \mathrm{~ms}$ were tested for the polymers containing BFRs. Further details of the rf-PGD-ToFMS equipment are described elsewhere. ${ }^{15,25}$

The ToFMS allows recording of completed mass spectra (mass resolving power of 2000 at $160 \mathrm{~m} / \mathrm{z}$ ) with a frequency of up to 100 $\mathrm{kHz}$, allowing a minimal time resolution of $10 \mu \mathrm{s}$. In our case, ToFMS was operated with an ion extraction frequency of $33 \mathrm{kHz}$ to reach a mass range up to $261 \mathrm{~m} / \mathrm{z}$. A mass spectrum has been recorded every $99 \mu$ s (the sum of three successive ToF extractions) to monitor the ion species along the pulse period. In order to improve the signal-to-noise ratio, 250 pulse profiles from 250 successive GD pulses have been averaged for all measurements. Analyte ion signals, both for elemental and molecular species, showed their maximum intensity in the after-peak region of the pulse. A detailed schematic showing the timing scheme and illustrating the ToF extraction, pulse width, and GD pulse profile is shown in a previous paper. ${ }^{19}$

In our case, once the optimum experimental conditions were established, the use of normalised intensities (with respect to ${ }^{12} \mathrm{C}^{+}$ ion signal) was performed to correct for instrumental instabilities and, thus, to obtain polyatomic relative abundances that will allow a more reliable identification of mass spectra. Three replicates of each BFR coating were carried out for all data evaluation. Linear discriminant analysis was performed using Statgraphics software (version Centurion XV.II).

\section{Results and discussion}

\section{Optimisation of GD operating conditions for the analysis of polymers containing BFRs}

Experimental conditions (Ar discharge pressure, rf forward power, pulse width and period) were chosen as a compromise between high sensitivity, both for elemental species and polyatomic ions, and reproducible analysis conditions. Taking into account that polymeric samples are thermally unstable, the appropriate selection of GD conditions is crucial to avoid sample overheating and so thermal desorption that would inevitably lead to fluctuations of ion signals, rendering quantitative analysis impractical. A polymer containing $4.6 \% \mathrm{Br}$ (as TBBPA) was used for the optimisation studies and the initial conditions were selected according to our previous experience using other polymeric samples $(200 \mathrm{~Pa}, 20 \mathrm{~W}, 2 \mathrm{~ms}$ pulse width and $4 \mathrm{~ms}$ period). ${ }^{19,20}$ Both elemental species and polyatomic ions were clearly observed in the mass spectra of polymers containing BFRs as shown later. Molecular information was mainly observed in the after-peak region of the pulse profile, so this time domain was used for data evaluation. In the pre-peak region, ion signals are mainly influenced by discharge gas species, whereas the plateau is characterised by a stabilisation of the operating conditions and so the beginning of the production of analyte ions, sputtered from the sample. The after-peak region is particularly interesting due to an increase of Ar metastable population which, through Penning ionization, conduces to an enhancement of analyte ionization. ${ }^{14}$ It is well known that the $\mathrm{Br}$ ionization potential $(11.8 \mathrm{eV})$ is higher than the energy of $\mathrm{Ar}$ metastable states (11.6 eV and $11.7 \mathrm{eV})$ and, therefore, Penning ionization could not take place for $\mathrm{Br}$. However, it has been reported that the $\mathrm{Br}$ ion signal along the GD pulse follows the same temporal profile as that observed for other atoms typically ionized by Penning processes $(e . g$. $\mathrm{Cu}$ ), showing both maximum intensity at the same time in the pulse profile. ${ }^{26}$

The optimisation of Ar discharge pressure and $\mathrm{rf}$ forward power was carried out using the ion signals obtained for ${ }^{79} \mathrm{Br}^{+}$ and several polyatomic ions (both with and without $\mathrm{Br}$ :

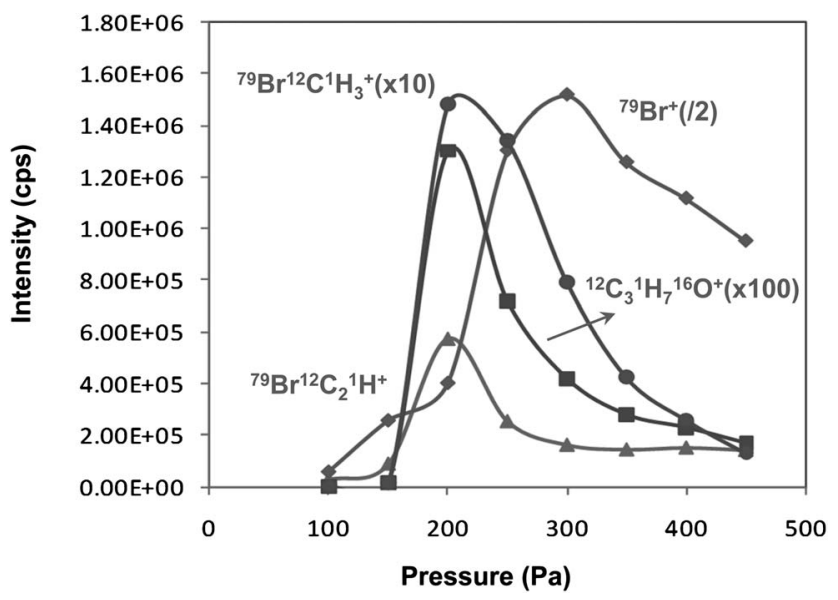

Fig. 1 Ion signal intensities measured for polymers containing TBBPA $(4.6 \% \mathrm{Br})$ over the entire after-peak time domain as a function of $\mathrm{Ar}$ discharge pressure and $\mathrm{rf}$. Operating pulse conditions: $2 \mathrm{~ms}$ pulse width and $4 \mathrm{~ms}$ pulse period, $15 \mathrm{~W}$ of $\mathrm{rf}$ forward power. 
${ }^{79} \mathrm{Br}^{12} \mathrm{C}_{2}{ }^{1} \mathrm{H}^{+},{ }^{79} \mathrm{Br}^{12} \mathrm{C}^{1} \mathrm{H}_{3}{ }^{+}$and ${ }^{12} \mathrm{C}_{3}{ }^{1} \mathrm{H}_{7}{ }^{16} \mathrm{O}^{+}$). Polymers are thermosensitive and, therefore, soft analysis conditions were used and samples were continuously refrigerated below $5^{\circ} \mathrm{C}$. The effect of discharge pressure was studied in the range of $100-450 \mathrm{~Pa}$ at 15 W delivered power. As can be seen in Fig. 1, element ${ }^{79} \mathrm{Br}^{+}$and polyatomic ion signals showed their maxima at different pressures (300 and $200 \mathrm{~Pa}$, respectively). In order to obtain a good sensitivity for both elemental and molecular species, a compromise at $200 \mathrm{~Pa}$ was finally selected for the subsequent experiments because the ${ }^{79} \mathrm{Br}^{+}$ion signal was not at a maximum but it was the better choice (as compared to signals obtained for ${ }^{79} \mathrm{Br}^{12} \mathrm{C}_{2}{ }^{1} \mathrm{H}^{+},{ }^{79} \mathrm{Br}^{12} \mathrm{C}^{1} \mathrm{H}_{3}{ }^{+}$and ${ }^{12} \mathrm{C}_{3}{ }^{1} \mathrm{H}_{7}{ }^{16} \mathrm{O}^{+}$at their optimum pressure). Concerning the rf forward, $15 \mathrm{~W}$ was finally selected to avoid desorption risks due to sample heating. It should be stated that the temporal responses of ${ }^{79} \mathrm{Br}^{+},{ }^{81} \mathrm{Br}^{+},{ }^{79} \mathrm{Br}^{12} \mathrm{C}_{2}{ }^{1} \mathrm{H}^{+}$, and ${ }^{79} \mathrm{Br}^{12} \mathrm{C}^{1} \mathrm{H}_{3}{ }^{+}$were monitored over $7 \mathrm{~min}$ at these selected experimental conditions, showing an excellent long-term stability in all cases (below $0.5 \%$ relative standard deviation). In addition, the isotopic ratio ${ }^{79} \mathrm{Br}^{+} / 81 \mathrm{Br}^{+}$was found to be $0.99 \pm 0.05$, which corresponds to a $4 \%$ deviation from the natural isotope abundance ratio.

As previously reported, ${ }^{27}$ milli- and microsecond pulse regimes can show different behaviour of the ionized species and, hence, a comparison study of both time domains was carried out for the analysis of polymers containing BFRs. Fig. $2 \mathrm{a}$ and $\mathrm{b}$ show the

a)

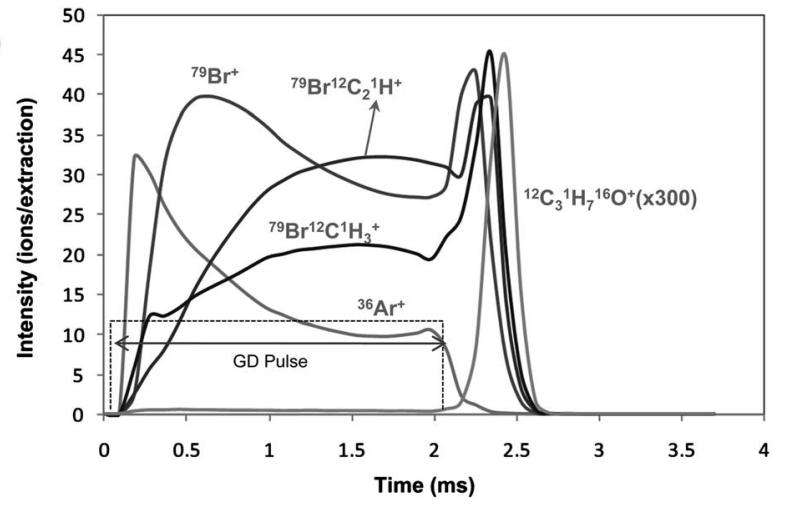

b)

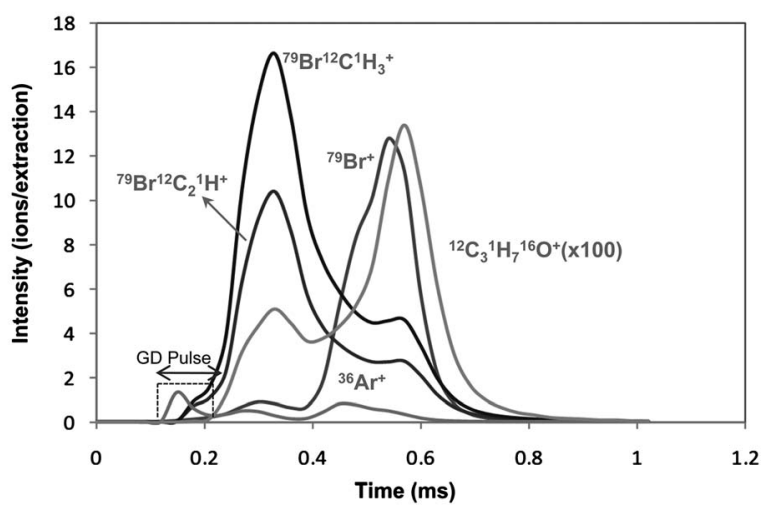

Fig. 2 Ion signal profile measured for the analysis of polymers containing TBBPA $(4.6 \% \mathrm{Br})$ by rf-PGD-ToFMS along the GD rf-pulse period. Operating conditions: $15 \mathrm{~W}, 200 \mathrm{~Pa}$. (a) Milliseconds pulse regime ( $2 \mathrm{~ms}$ pulse width and $4 \mathrm{~ms}$ period) and (b) microseconds pulse regime $(100 \mu$ s pulse width and $1100 \mu$ s period). pulse profiles observed for the gas ion $\left({ }^{36} \mathrm{Ar}^{+}\right)$and several polymer specific ions $\left({ }^{12} \mathrm{C}_{3}{ }^{1} \mathrm{H}_{7}{ }^{16} \mathrm{O}^{+},{ }^{79} \mathrm{Br}^{+},{ }^{79} \mathrm{Br}^{12} \mathrm{C}^{1} \mathrm{H}_{3}{ }^{+}\right.$and ${ }^{79} \mathrm{Br}^{12} \mathrm{C}_{2}{ }^{1} \mathrm{H}^{+}$) in the milli- and microsecond pulse regimes, respectively. As can be seen, the highest intensities for the analytes were always obtained in the after-peak region and the duration of this region, after the end of the power supply pulse, seems to be rather independent of the pulse width applied, being in both cases around $600 \mu \mathrm{s}$. However, several differences were observed between milli- and microsecond pulse regimes: the intensities ratio "after-peak/plateau" were higher in the microsecond regime. Also, in the millisecond regime only one maximum for the ion signals in the after-peak region is apparent, whereas two maxima, at different delay times, could be observed using microsecond pulses (Fig. 2b). Moreover, not all the ions showed their maxima at the same delay time after the end of the pulse: in the millisecond regime the maximum signal for ${ }^{79} \mathrm{Br}^{+}$ appeared just after the end of the GD pulse $(\sim 0.18 \mathrm{~ms})$ followed by ${ }^{79} \mathrm{Br}^{12} \mathrm{C}_{2}{ }^{1} \mathrm{H}^{+}$and ${ }^{79} \mathrm{Br}^{12} \mathrm{C}^{1} \mathrm{H}_{3}{ }^{+}(\sim 0.27 \mathrm{~ms})$, whereas in the microsecond regime polyatomic ions with $\mathrm{Br}\left({ }^{79} \mathrm{Br}^{12} \mathrm{C}_{2}{ }^{1} \mathrm{H}^{+}\right.$and $\left.{ }^{79} \mathrm{Br}^{12} \mathrm{C}^{1} \mathrm{H}_{3}{ }^{+}\right)$showed their maxima before that of ${ }^{79} \mathrm{Br}^{+}(\sim 0.12$ and $0.33 \mathrm{~ms}$, respectively). The polyatomic ion ${ }^{12} \mathrm{C}^{1} \mathrm{H}_{7}{ }^{16} \mathrm{O}^{+}$ appeared with longer delay times for both time regimes (this could be attributed to after the pulse recombination processes taking place in the later after-peak region). Due to the complexity of the reaction processes in the plasma further fundamental studies would be required in order to provide a complete explanation of the observed behaviours for gas phase ions.

\section{Analytical performance characterisation}

Taking into account the found differences between the pulse profiles corresponding to the milli- and microsecond pulse domains, the analytical performance characteristics for ${ }^{79} \mathrm{Br}^{+}$and two polyatomic ions $\left({ }^{79} \mathrm{Br}^{12} \mathrm{C}^{1} \mathrm{H}_{3}{ }^{+}\right.$and $\left.{ }^{79} \mathrm{Br}^{12} \mathrm{C}_{2}{ }^{1} \mathrm{H}^{+}\right)$were determined by rf-GD-ToFMS using both pulse regimes. For this purpose, polymers with TBBPA (containing a $\mathrm{Br}$ concentration up to $27.9 \%$ ) were employed, and normalised intensities (with respect to ${ }^{12} \mathrm{C}^{+}$ion signal) were always used. Fig. 3 shows the weighted calibration curves obtained for ${ }^{79} \mathrm{Br}^{+},{ }^{79} \mathrm{Br}^{12} \mathrm{C}^{1} \mathrm{H}_{3}{ }^{+}$and ${ }^{79} \mathrm{Br}^{12} \mathrm{C}_{2}{ }^{1} \mathrm{H}^{+}$in the millisecond pulse regime (the error bars

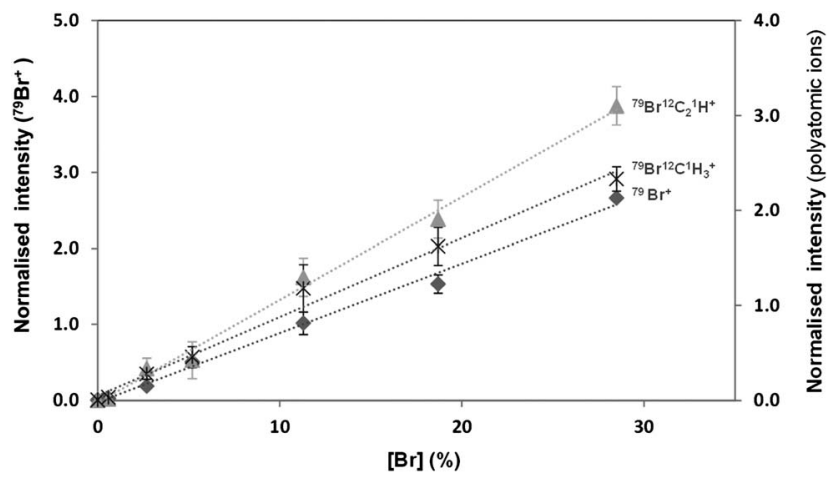

Fig. $3{ }^{79} \mathrm{Br}^{+},{ }^{79} \mathrm{Br}^{12} \mathrm{C}^{1} \mathrm{H}_{3}{ }^{+}$and ${ }^{79} \mathrm{Br}^{12} \mathrm{C}_{2}{ }^{1} \mathrm{H}^{+}$normalised calibration curves obtained for the analysis of polymers with TBBPA $(0-27.9 \% \mathrm{Br})$ by rfPGD-ToFMS. Operating conditions: $200 \mathrm{~Pa}, 15 \mathrm{~W}, 2 \mathrm{~ms}$ pulse width and $4 \mathrm{~ms}$ period. 
Table 2 Detection limits obtained for the analysis of polymers containing TBBPA by rf-PGD-ToFMS in the milli- and microsecond pulse regimes (the length of the pulse is shown in brackets)

\begin{tabular}{lll}
\hline Time pulse regime & Ions & DLs $(\% \mathrm{Br})$ \\
\hline Microsecond rf-PGD-ToFMS (100 $\mu \mathrm{s})$ & ${ }^{79} \mathrm{Br}^{+}$ & 0.175 \\
& ${ }^{79} \mathrm{Br}^{12} \mathrm{C}^{1} \mathrm{H}_{3}^{+}$ & 0.358 \\
Millisecond rf-PGD-ToFMS (2 ms) & ${ }^{79} \mathrm{Br}^{72} \mathrm{C}_{2}{ }^{19} \mathrm{H}^{+}$ & 0.090 \\
& ${ }^{79} \mathrm{Br}^{+}$ & 0.037 \\
& ${ }^{79} \mathrm{Br}^{12} \mathrm{C}^{1} \mathrm{H}_{3}{ }^{+}$ & 0.066 \\
& ${ }^{1} \mathrm{H}^{+}$ & 0.043 \\
\hline
\end{tabular}

correspond to the standard deviation obtained for three independent measurements). Moreover, Table 2 collects the detection limits (DLs) obtained in the milli- and microsecond regimes, calculated by using the $3 \sigma$ criterion. As can be observed, better DLs were obtained using a millisecond pulse regime. In addition, a higher number of polyatomic ions and up to higher masses could be found in such a millisecond pulse regime. Thus, this latter regime was selected for all the subsequent measurements. On the other hand, it should be stressed that improved DLs were obtained for elemental bromine by rf-PGD-ToFMS, as compared to those previously obtained by rf-GD-OES analysing similar polymers containing TBBPA. ${ }^{28}$

\section{Polymers fingerprinting: polymers containing TBBPA}

The capabilities of rf-PGD-ToFMS for mass spectrometric fingerprinting of polymers containing different BFR compounds in their structure have been investigated as well. Previous studies proved that some polymer characterisation can be achieved based on the detected polyatomic ions. ${ }^{19,20}$ Thus, the presence of representative polyatomic ions, related to the BFR or perhaps formed in the plasma after sputtering of the polymeric material, can be investigated as markers for the identification and discrimination between different BFRs (i.e. for obtaining the polymers fingerprint). First, polymers with different concentrations of TBBPA (in the range of $0-27.9 \% \mathrm{Br}$ ) were employed for the selection of the mass spectrum regions exhibiting peculiar polyatomic ions. Fig. 4 shows the averaged mass spectra obtained for a blank polymer (Fig. 4a) and a polymer containing $27.9 \% \mathrm{Br}$ from TBBPA (Fig. 4b). As can be observed, the most

a)


Fig. 4 Normalised mass spectra obtained by rf-PGD-ToFMS. Operating conditions: $200 \mathrm{~Pa}, 15 \mathrm{~W}, 2$ ms pulse width and 4 ms period. (a) Polymeric matrix $(0 \% \mathrm{Br})$ and $(\mathrm{b})$ polymer with TBBPA $(27.9 \% \mathrm{Br})$. 
a)

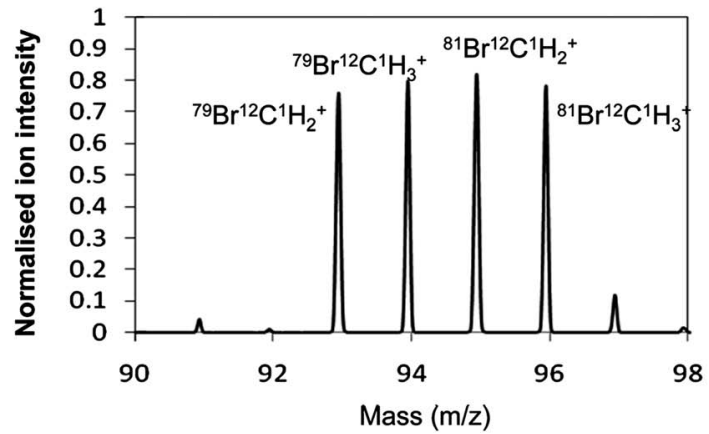

b)

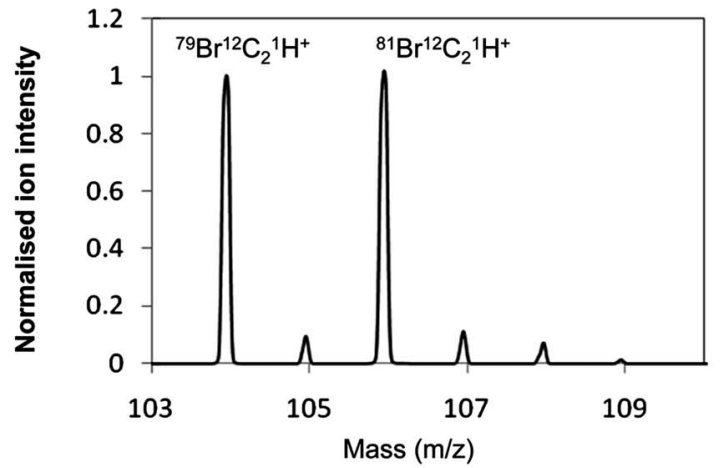

c)

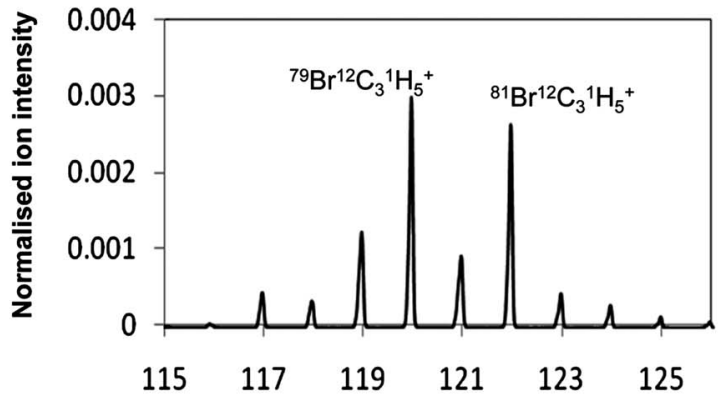

d)

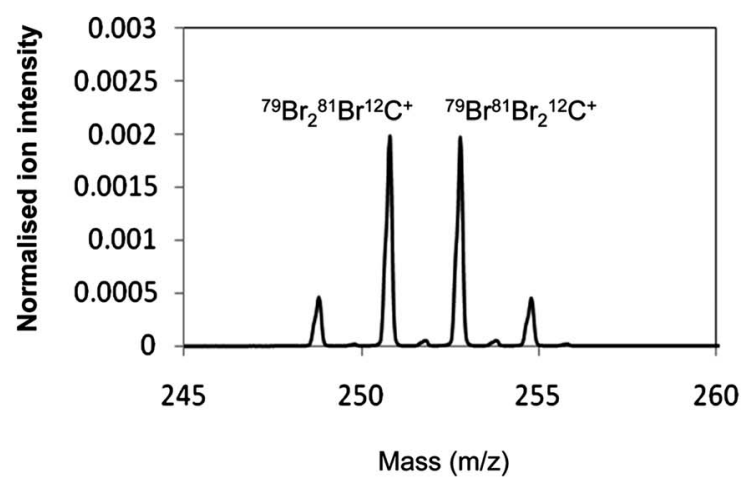

Fig. 5 Representative mass spectrum regions (normalised with respect to ${ }^{12} \mathrm{C}^{+}$ion signal) obtained for the polymer containing TBBPA $(27.9 \%$ Br) by rf-PGD-ToFMS. (a) $90-98 \mathrm{~m} / z$; (b) $103-110 \mathrm{~m} / \mathrm{z}$; (c) $115-126 \mathrm{~m} / \mathrm{z}$ and (d) $245-260 \mathrm{~m} / \mathrm{z}$.

abundant ions were related in both cases to the discharge gas species (e.g. ${ }^{40} \mathrm{Ar}^{+},{ }^{40} \mathrm{Ar}^{1} \mathrm{H}^{+}$and $\left.{ }^{40} \mathrm{Ar}_{2}{ }^{+}\right)$and those coming from the polymeric matrix (polyatomic ions in the low mass range, such as ${ }^{12} \mathrm{C}_{2}{ }^{1} \mathrm{H}_{2}{ }^{+},{ }^{12} \mathrm{C}^{1} \mathrm{H}^{16} \mathrm{O}^{+}$and ${ }^{12} \mathrm{C}_{3}{ }^{1} \mathrm{H}_{2}{ }^{16} \mathrm{O}^{+}$). However, for polymers containing TBBPA, not only elemental ${ }^{79} \mathrm{Br}^{+}$ions but also specific polyatomic ions above $90 \mathrm{~m} / \mathrm{z}$, were clearly found in the mass spectrum (Fig. 4b). As these ions were not present in the blank mass spectrum, they could be attributed to the BFR presence.

A careful selection of the polyatomic ions throughout the mass spectrum was carried out to obtain a proper mass-spectral fingerprint for polymers containing TBBPA and, hence, to develop an effective screening method for estimating their presence. Fig. 5 collects four different regions of the mass spectrum obtained for the analysis of polymers with TBBPA $(27.9 \% \mathrm{Br})$ by rf-PGD-ToFMS. As can be seen, the intensity of the polyatomic ions was lower at higher masses, decreasing up to a 400 -fold factor from $94 \mathrm{~m} / \mathrm{z}$ to $251 \mathrm{~m} / \mathrm{z}$ (Fig. 5a and d, respectively). In the four selected regions, the most abundant signals can be assigned to polyatomic ions containing $\mathrm{Br}\left(\right.$ e.g. ${ }^{79} \mathrm{Br}^{12} \mathrm{C}^{1} \mathrm{H}_{2}{ }^{+},{ }^{79} \mathrm{Br}^{12} \mathrm{C}_{2}{ }^{1} \mathrm{H}^{+}$, ${ }^{79} \mathrm{Br}^{12} \mathrm{C}_{3}{ }^{1} \mathrm{H}_{5}{ }^{+}$and ${ }^{79} \mathrm{Br}_{2}{ }^{81} \mathrm{Br}^{12} \mathrm{C}^{+}$). It should be highlighted that the measured natural isotope ratio between ${ }^{79} \mathrm{Br}^{+}$and ${ }^{81} \mathrm{Br}^{+}$ions remained constant in the polyatomic ions (e.g. ${ }^{79} \mathrm{Br}^{12} \mathrm{C}_{2}{ }^{1} \mathrm{H}^{+}$and $\left.{ }^{81} \mathrm{Br}^{12} \mathrm{C}_{2}{ }^{1} \mathrm{H}^{+}\right)$, indicating that such molecular species were free from possible spectral interferences. Moreover, the higher the

a)

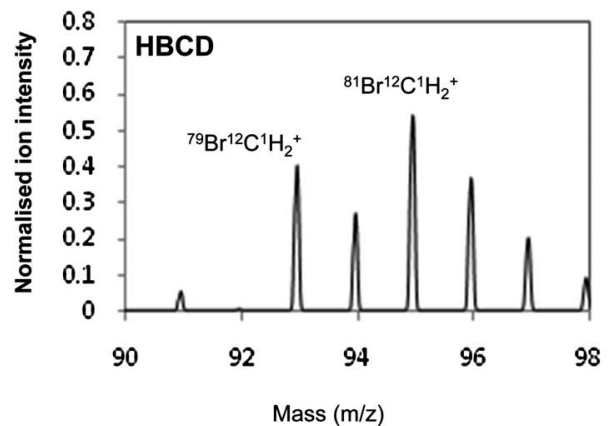

b)

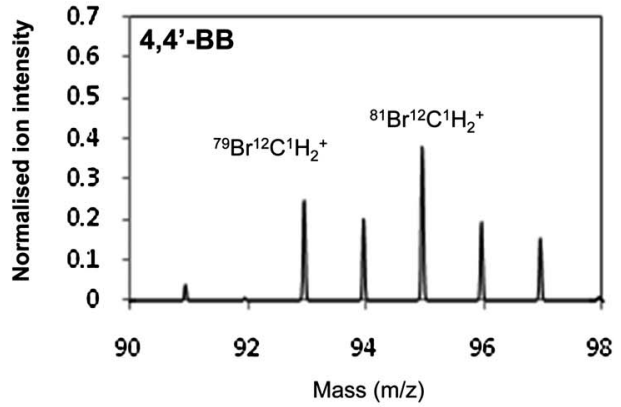

c)

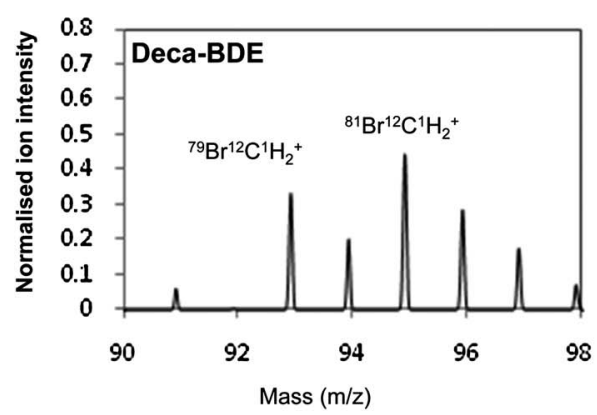

Fig. 6 Normalised mass spectra $(90-98 \mathrm{~m} / \mathrm{z}$ region) obtained for the analysis of polymers containing BFRs $(27.9 \% \mathrm{Br})$ by rf-GD-ToFMS. Operating conditions: $200 \mathrm{~Pa}, 15 \mathrm{~W}, 2 \mathrm{~ms}$ pulse width and $4 \mathrm{~ms}$ period. (a) HBCD; (b) 4,4'-BB and (c) Deca-BDE. 
concentration of $\mathrm{Br}$ in the polymer, the higher the polyatomic ion signals (this trend was observed for all the polyatomic ions identified throughout the mass spectra ranging from $90 \mathrm{~m} / \mathrm{z}$ to $260 \mathrm{~m} / \mathrm{z}$ ). In other words, although the intensity of the signals increased linearly with the $\mathrm{Br}$ concentration in each species, the polyatomic relative abundances measured for such polyatomic ions remained always constant.

\section{Screening of polymers with BFRs through their mass-spectral fingerprint}

In order to investigate the potential of rf-PGD-ToFMS to discriminate polymers containing different BFRs (by comparing their mass-spectral fingerprint or their polyatomic relative abundance), the analysis of Deca-BDE, HBCD and 4,4'-BB polymers was carried out at the rf-PGD-ToFMS optimised experimental conditions. Polymers containing 27.9\% $\mathrm{Br}$ total concentration were employed in all cases in order to have a good sensitivity at the high mass spectrum regions. Screening capabilities based on the polyatomic ions nature and their polyatomic relative abundance at the different mass spectrum regions were investigated. As an example, Fig. 6 collects the normalised mass spectra obtained in the 90-98 $\mathrm{m} / \mathrm{z}$ region for HBCD, 4,4'-BB and Deca-BDE polymers (the corresponding mass region for TBBPA can be seen in Fig. 5a). Interestingly, virtually the same polyatomic ions (pattern) were identified for all the BFRs. However, abundances obtained for such polyatomics in TBBPA (Fig. 5a) were significantly different, as compared to those obtained for

\section{a)}

b)


c)

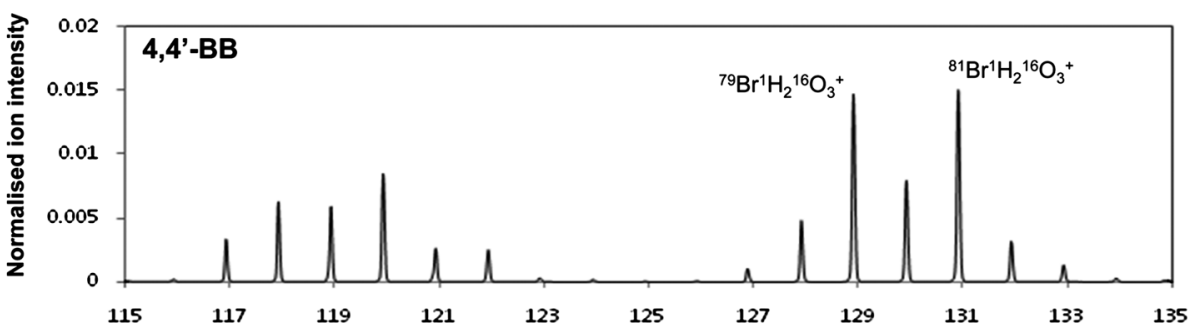

d)

$\operatorname{Mass}(\mathrm{m} / \mathrm{z})$

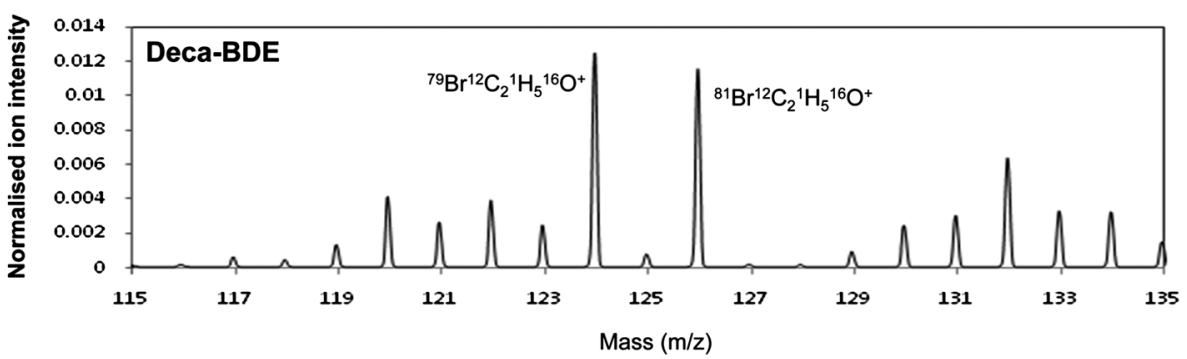

Fig. 7 Normalised mass spectra (115-135 m/z region) obtained for the analysis of polymers containing BFRs (27.9\% Br) by rf-GD-ToFMS. Operating conditions: $200 \mathrm{~Pa}, 15 \mathrm{~W}, 2$ ms pulse width and 4 ms period. (a) TBBPA; (b) HBCD; (c) 4,4'-BB and (d) Deca-BDE. 




Fig. 8 Identification of polymers containing different BFRs (TBBPA, Deca-BDE, HBCD and 4,4'-BB) by rf-PGD-ToFMS using LDA for differentiation.

HBCD , 4,4'-BB and Deca-BDE polymers (Fig. 6a-c). In the first case, ${ }^{79} \mathrm{Br}^{12} \mathrm{C}^{1} \mathrm{H}_{2}{ }^{+},{ }^{79} \mathrm{Br}^{12} \mathrm{C}^{1} \mathrm{H}_{3}{ }^{+},{ }^{81} \mathrm{Br}^{12} \mathrm{C}^{1} \mathrm{H}_{2}{ }^{+}$and ${ }^{81} \mathrm{Br}^{12} \mathrm{C}^{1} \mathrm{H}_{3}{ }^{+}$ion signals exhibited a similar intensity in the normalised mass spectrum, whereas $\mathrm{HBCD}, 4,4^{\prime}-\mathrm{BB}$ and Deca-BDE polymers showed higher intensities for ${ }^{79} \mathrm{Br}^{12} \mathrm{C}^{1} \mathrm{H}_{2}{ }^{+}$and ${ }^{81} \mathrm{Br}^{12} \mathrm{C}^{1} \mathrm{H}_{2}{ }^{+}$than for the other polyatomics. A different mass region (115-135 m/z) can be seen in Fig. 7 for the four selected BFRs investigated. In this case, three of the samples could be easily distinguished based on their polyatomic relative abundances since the most intense polyatomic ions directly depend on the $\mathrm{BFR}$ exposed to the discharge; ${ }^{79} \mathrm{Br}^{12} \mathrm{C}_{3}{ }^{1} \mathrm{H}_{5}{ }^{+}$and ${ }^{81} \mathrm{Br}^{12} \mathrm{C}_{3}{ }^{1} \mathrm{H}_{5}{ }^{+}$for TBBPA, ${ }^{79} \mathrm{Br}^{1} \mathrm{H}_{2}{ }^{16} \mathrm{O}_{3}{ }^{+}$and ${ }^{81} \mathrm{Br}^{1} \mathrm{H}_{2}{ }^{16} \mathrm{O}_{3}{ }^{+}$for $4,4^{\prime}-\mathrm{BB}$, and ${ }^{79} \mathrm{Br}^{12} \mathrm{C}_{2}{ }^{1} \mathrm{H}_{5}{ }^{16} \mathrm{O}^{+}$ and ${ }^{81} \mathrm{Br}^{12} \mathrm{C}_{2}{ }^{1} \mathrm{H}_{5}{ }^{16} \mathrm{O}^{+}$for Deca-BDE. The polymer with HBCD showed similar polyatomic relative abundances to TBBPA, only with a lower sensitivity. However, those two polymers with TBBPA and HBCD could be easily distinguished by using the polyatomic relative abundances at the mass region $90-98 \mathrm{~m} / \mathrm{z}$ (Fig. 5a and 6a, respectively).

To further visualise the differences between the mass spectra obtained for the four polymers with different BFR compounds and, therefore, to develop a robust screening method, LDA was carried out with the experimental data. This statistical analysis proved to be very helpful especially in the cases of rather similar mass spectra. The analysis of each polymer containing BFRs $(27.9 \% \mathrm{Br})$ was performed three times to examine the reproducibility in the LDA score plots and eight variables (the most intense polyatomic ions at the different mass regions; ${ }^{79} \mathrm{Br}^{12} \mathrm{C}^{1} \mathrm{H}_{2}{ }^{+},{ }^{81} \mathrm{Br}^{12} \mathrm{C}^{1} \mathrm{H}_{2}{ }^{+},{ }^{79} \mathrm{Br}^{12} \mathrm{C}_{3}{ }^{1} \mathrm{H}_{5}{ }^{+},{ }^{81} \mathrm{Br}^{12} \mathrm{C}_{3}{ }^{1} \mathrm{H}_{5}{ }^{+}$, ${ }^{79} \mathrm{Br}^{12} \mathrm{C}_{2}{ }^{1} \mathrm{H}_{5}{ }^{16} \mathrm{O}^{+}, \quad{ }^{81} \mathrm{Br}^{12} \mathrm{C}_{2}{ }^{1} \mathrm{H}_{5}{ }^{16} \mathrm{O}^{+}, \quad{ }^{79} \mathrm{Br}^{1} \mathrm{H}_{2}{ }^{16} \mathrm{O}_{3}{ }^{+}$and ${ }^{81} \mathrm{Br}^{1} \mathrm{H}_{2}{ }^{16} \mathrm{O}_{3}{ }^{+}$) were taken into account for the calculation. Fig. 8 shows the discriminant functions graph obtained for the identification of polymers containing the different BFRs under scrutiny (TBBPA, Deca-BDE, HBCD and 4,4'-BB) by using LDA. As can be seen, a neat and correct differentiation of the four polymers was carried out. Moreover, several polymers with different TBBPA concentrations (in the range of $0.6-16.2 \% \mathrm{Br}$ ) were also evaluated as unknown samples and all of them were successfully classified as polymers containing TBBPA with a probability of 1 .

\section{Conclusions}

Promising and convenient capabilities of rf-PGD-ToFMS for mass spectrometric fingerprinting of polymers containing BFRs have been demonstrated. Representative polyatomic ions related to the sample composition or formed in the plasma after sputtering of the polymeric material have been identified and applied to reliable discrimination between four polymers containing BFRs (TBBPA, Deca-BDE, 4,4'-BB and HBCD). Successful screening of samples was achieved based on the polyatomic ion signals detected and their abundance patterns in several mass spectrum regions. Advantages of rf-PGD-ToFMS as a fast screening method include the absence of sample preparation stages before the measurement and comparatively good sensitivity. Therefore, our results here indicate the analytical potential of this new analytical tool as a convenient alternative to conventional methods of analysis for estimating and assessing the presence of hazardous BFRs in paintings and organic polymer coatings.

\section{Acknowledgements}

Financial support from "Plan Nacional de I + D + I" (Spanish Ministry of Science and Innovation and FEDER Programme) through MAT2010-20921-C02 is acknowledged. B. Fernandez acknowledges financial support from "Juan de la Cierva" Research Program of the Ministry of Science and Innovation of Spain co-financed by the European Social Fund. Finally, we are especially thankful for the contract with Horiba Jobin Yvon for the loan of the GD-ToFMS instrument.

\section{References}

1 M. Alaee, P. Arias, A. Sjödin and Å. Bergman, Environ. Int., 2003, 29, 683-689.

2 Bromine Science and Environmental Forum, www.bsef.com.

3 J. Legler and A. Brouwer, Environ. Int., 2003, 29, 879-885.

4 Directive 2002/95/EC of the European Parliament and of the Council, Off. J. Eur. Communities: Legis., 2003, 37, 19.

5 Commission Decision 2005/618/EC, Off. J. Eur. Communities: Legis., 2005, 214, 65.

6 G. Mascolo, V. Locaputo and G. Mininni, J. Chromatogr., A, 2010, 1217, 4601-4611.

7 R. Zeleny, S. Voorspoels, M. Ricci, R. Becker, C. Jung, W. Bremser, M. Stittidech, N. Panyawathanakit, W. F. Wong, S. M. Choi, K. C. Lo, W. Y. Yeung, D. H. Kim, J. Han, J. Ryu, S. Mingwu, W. Chao, M. M. Schantz, K. A. Lippa and S. Matsuyama, Anal. Bioanal. Chem., 2010, 396, 1501-1511.

8 N. Ali, S. Harrad, D. Muenhor, H. Neels and A. Covaci, Anal. Bioanal. Chem., 2011, 400, 3073-3083.

9 J. Pisonero, B. Fernández and D. Günther, J. Anal. At. Spectrom., 2009, 24, 1145-1160.

10 C. M. Mahoney, Mass Spectrom. Rev., 2010, 29, 247-293.

11 C. R. Shick, Jr, P. A. DePalma, Jr and R. K. Marcus, Anal. Chem., 1996, 68, 2113-2121.

12 L. Li, C. M. Barshick, J. T. Millay, A. V. Welty and F. L. King, Anal. Chem., 2003, 75, 3953-3961.

13 R. Pereiro, A. Solà-Vázquez, L. Lobo, J. Pisonero, N. Bordel, J. M. Costa and A. Sanz-Medel, Spectrochim. Acta, Part B, 2011, 66, 399-412.

$14 \mathrm{Ph}$. Belenguer, M. Ganciu, Ph. Guillot and Th. Nelis, Spectrochim. Acta, Part B, 2009, 64, 623-641.

15 L. Lobo, J. Pisonero, N. Bordel, R. Pereiro, A. Tempez, P. Chapon, J. Michler, M. Hohl and A. Sanz-Medel, J. Anal. At. Spectrom., 2009, 24, 1373-1381.

16 J. N. Robertson-Honecker, N. Zhang, A. Pavkovich and F. L. King, J. Anal. At. Spectrom., 2008, 23, 1508-1517.

17 N. Zhang and F. L. King, J. Anal. At. Spectrom., 2009, 24, 1489-1497.

18 G. Gu, M. DeJesus and F. L. King, J. Anal. At. Spectrom., 2011, 26, 816-821.

19 N. Tuccitto, L. Lobo, A. Tempez, I. Delfanti, P. Chapon, S. Canulescu, N. Bordel, J. Michler and A. Licciardello, Rapid Commun. Mass Spectrom., 2009, 23, 549-556. 
20 L. Lobo, N. Tuccitto, N. Bordel, R. Pereiro, J. Pisonero, A. Licciardello, A. Tempez, P. Chapon and A. Sanz-Medel, Anal. Bioanal. Chem., 2010, 396, 2863-2869.

21 S. Canulescu, J. Whitby, K. Fuhrer, M. Hohl, M. Gonin, T. Horvath and J. Michler, J. Anal. At. Spectrom., 2009, 24, 178-180.

22 M. C. Jecklin, G. Gamez and R. Zenobi, Analyst, 2009, 134, 16291636.

23 R. A. Johnson and D. W. Wichern, Applied Multivariate Statistical Analysis, Prentice Hall, Upper Saddle River, NJ, USA, 2007.

24 M. Hohl, A. Kanzari, J. Michler, Th. Nelis, K. Fuher and M. Gonin, Surf. Interface Anal., 2006, 38, 292-295.
25 I. S. Molchan, G. E. Thompson, P. Skeldon, N. Trigoulet, P. Chapon, A. Tempez, J. Malherbe, L. Lobo Revilla, N. Bordel, Ph. Belenguer, T. Nelis, A. Zahri, L. Therese, Ph. Guillot, M. Ganciu, J. Michler and M. Hohl, J. Anal. At. Spectrom., 2009, 24, 734-741.

26 C. González, N. Bordel, R. Pereiro and A. Sanz-Medel, J. Mass Spectrom., 2011, 46, 757-763.

27 C. González, J. Pisonero, R. Pereiro, N. Bordel, P. Mazón and A. Sanz-Medel, J. Anal. At. Spectrom., 2010, 25, 1612-1617.

28 A. Solá-Vázquez, A. Martín, J. M. Costa-Fernandez, J. Ruiz Encinar, N. Bordel, R. Pereiro and A. Sanz-Medel, Anal. Bioanal. Chem., 2007, 389, 683-690. 